\title{
New Challenges for the Design of High Value Plant Products: Stabilization of Anthocyanins in Plant Vacuoles
}

\author{
Valentina Passeri, Ronald Koes and Francesca M. Quattrocchio* \\ Plant Development and (Epi)Genetics, Swammerdam Institute of Life Sciences, University of Amsterdam, Amsterdam, \\ Netherlands
}

\section{OPEN ACCESS}

Edited by:

Eugenio Benvenuto,

Italian National Agency for New Technologies, Energy and Sustainable

Economic Development, Italy

Reviewed by:

Laura Jaakola,

UiT The Arctic University of Norway,

Norway

Massimiliano Tattini, The National Research Council of Italy, Italy

${ }^{*}$ Correspondence: Francesca M. Quattrocchio

f.quattrocchio@uva.nl

Specialty section:

This article was submitted to

Plant Biotechnology,

a section of the journal

Frontiers in Plant Science

Received: 09 December 2015

Accepted: 29 January 2016

Published: 16 February 2016

Citation:

Passeri V, Koes $R$ and Quattrocchio FM (2016) New Challenges for the Design of High Value Plant Products: Stabilization of Anthocyanins in Plant Vacuoles.

Front. Plant Sci. 7:153.

doi: 10.3389/fpls.2016.00153
In the last decade plant biotechnologists and breeders have made several attempt to improve the antioxidant content of plant-derived food. Most efforts concentrated on increasing the synthesis of antioxidants, in particular anthocyanins, by inducing the transcription of genes encoding the synthesizing enzymes. We present here an overview of economically interesting plant species, both food crops and ornamentals, in which anthocyanin content was improved by traditional breeding or transgenesis. Old genetic studies in petunia and more recent biochemical work in brunfelsia, have shown that after synthesis and compartmentalization in the vacuole, anthocyanins need to be stabilized to preserve the color of the plant tissue over time. The final yield of antioxidant molecules is the result of the balance between synthesis and degradation. Therefore the understanding of the mechanism that determine molecule stabilization in the vacuolar lumen is the next step that needs to be taken to further improve the anthocyanin content in food. In several species a phenomenon known as fading is responsible for the disappearance of pigmentation which in some case can be nearly complete. We discuss the present knowledge about the genetic and biochemical factors involved in pigment preservation/destabilization in plant cells. The improvement of our understanding of the fading process will supply new tools for both biotechnological approaches and marker-assisted breeding.

Keywords: Anthocyanin, fading, product stabilization, health-promoting products, vacuole

\section{INTRODUCTION}

Anthocyanins are flavonoid pigments conferring red, blue and purple colors to plant tissues. Because they are visible to the naked eye, these pigments are a model for genetics, molecular biology and cell biology. Consequently, both structural and regulatory genes of the biosynthetic pathway are identified in a plethora of species (Figure 1A). A complex of highly conserved WD40, bHLH and MYB proteins (MBW complex) activates the transcription of structural genes encoding enzymes of the anthocyanin pathway (Koes et al., 2005; Jaakola, 2013). In all species analyzed, the WD40 is expressed ubiquitously, whereas expression of bHLH and MYB factors is confined to pigmented tissues. The bHLH regulators hook up with the WD40 partner to activate downstream genes involved in multiple pathways like anthocyanin and tannin production, vacuolar acidification and cell shape, through interactions with different MYB proteins, which are main determinants of the specificity of the complex (Koes et al., 2005; Ramsay and Glover, 2005). 
The MYB component of the MBW complex that activate the (pro)anthocyanin pathway is able to activate transcription of its bHLH partner and is therefore consider a "master regulator" as it can, alone, induce activation of the pathway (Spelt et al., 2000; Nesi et al., 2001; Kiferle et al., 2015).After synthesis, anthocyanins are transported to the vacuolar lumen where they are stored. This process is studied by several groups (Francisco et al., 2013; Chanoca et al., 2015; Hu et al., 2016) but it is still not fully understood in spite of the substantial role it might play in the final anthocyanin content in plant tissues.

Plant products rich in anthocyanin like berries, eggplant, grape, and red cabbage, are part of the human diet. Several studies reported that anthocyanin-intake prevents the onset and development of degenerative diseases. Some example of the health promoting effects of anthocyanins are stimulation of visual acuity and reduction of retinal damage (Kalt et al., 2014; Giampieri et al., 2015; Wang et al., 2015), decreased expression of inflammatory biomarkers (Samadi et al., 2015), diminished risk of type-2 diabetes mellitus (Guo and Ling, 2015), reduced weight gain (Titta et al., 2010) and anti-cancerogenic activity (Butelli et al., 2008; Forbes-Hernandez et al., 2015; Vlachojannis et al., 2015). By in vitro simulation of the gastrointestinal system and animal and human tests, anthocyanins were shown to remain bio-accessible during digestion (Kalt et al., 2014; Oliveira and Pintado, 2015; Olejnik et al., 2016).

The presence of anthocyanin in plant tissues positively affects their market value in addition by increasing the aesthetical appeal and by reducing softening, shriveling, rotting and fungal infection (Zhang et al., 2015c). Furthermore color novelty is a major driving force in the ornamentals and cut flower industry.

Increased anthocyanin content is, for all mentioned reasons, an obvious goal for crop breeding and biotechnology. Therefore combinations of classical and molecular methods, have been used to generate new varieties with enhanced anthocyanin content as well as different colors and pigmentation patterns.

Till now, research in ornamental and food crops aimed to alter genes controlling anthocyanin synthesis, since it was taken for granted that the end products are stable once they are deposited in the vacuole. However, for fruits, flowers and leaves of several species it is known that anthocyanin may disappear again during development in a regulated manner that depends, for example on environmental conditions (Oren-Shamir, 2009).

Here we review the state of the art in improving anthocyanin production in plant tissues and report recent insights into the (in)stability of anthocyanins in vacuoles, suggesting that the understanding of the mechanism behind anthocyanin stabilization in planta is required for breeding and biotechnology to take the next step toward plant varieties with increased economical and nutraceutical value.

\section{STUDYING FLOWER PIGMENTATION TAUGHT US HOW TO COLOR OUR FOOD}

Much of the current knowledge on anthocyanin chemistry and genetics originates from studies on flower pigmentation in model species. Some of the results have been applied to generate new varieties of cut flowers and ornamental flowering plants with novel colors and pigmentation patterns.

The substrate specificity of the enzymes of the anthocyanin pathway determines the final pattern of chemical decorations and thereby the pigment color (Provenzano et al., 2014; Rinaldo et al., 2015). Together with the understanding of the biosynthetic pathway regulation (Koes et al., 2005; Jaakola, 2013), this knowledge was applied to enhance the nutraceutical value and the appeal of several economically relevant plant products.

Traditional breeding has produced an array of colors in different species but the top-selling cut flowers rose, chrysanthemum, carnation and lily do not have blue in their pallet, while petunia lacks red/orange (Holton and Tanaka, 1994; Forkmann and Heller, 1999). New colors were obtained changing the decoration pattern on the basic skeleton of anthocyanins (Figure 1A) in roses, chrysanthemum and carnations. The expression of an exogenous flavonol $3^{\prime}, 5^{\prime}$ hydroxylase $\left(F 3^{\prime} 5^{\prime} \mathrm{H}\right)$ combined with an heterologous dihydroflavonol 4-reductase $(D F R)$ accepting a three-hydroxylated substrate, leads to accumulation of delphinidin (Katsumoto et al., 2007; Tanaka et al., 2008) and to lilac and purple flowers in rose and carnation (Figure 1B). Orange and red colors from pelargonidin-based anthocyanins were obtained in petunia by suppressing the flavonoid hydroxylases $F 3^{\prime} H$ and $F 3^{\prime} 5^{\prime} H$, and expressing a $D F R$ with specificity for mono-hydroxylated substrates (Meyer et al., 1987). New colors are also obtained by changing the anthocyanin pattern of methylation, glycosylation, and acylation (Provenzano et al., 2014; Du et al., 2015; Morita et al., 2015).

The dynamics of metabolic flows affects channeling of precursors toward anthocyanin production (Zvi et al., 2012; Sheehan et al., 2015; Zhang et al., 2015b) and this should be considered when designing strategies to generate genotypes with new colors or enhanced anthocyanin content.

Flower pigmentation patterns originate from differential expression of the structural genes in different cells. While irregular patterns are mostly due to transposon insertions in structural and/or regulatory genes (Figure 1C; Lister et al., 1993; Spelt et al., 2000; Itoh et al., 2002), flecks, sector veins and coloration of different flower parts are due to differential expression of genes encoding for MYB proteins of the MBW transcription complex regulating the anthocyanin pathway.

In the genus Antirrhinum variation in activity of the MYB genes Rosea and Venosa regulates pigmentation in different flower parts (Stracke et al., 2001) and in petunia, different members of the same clade of MYB regulators independently pigment petals, anthers and tube (Tornielli et al., 2009). Similarly, in Phalaenopsis orchids three MYBs control spotting and venation patterns by activation of structural genes expression in the sepals/petals (Hsu et al., 2015). Ectopic expression of the Arabidopsis anthocyanin MYB regulator PAP1 in roses results in enhanced pigmentation in leaves and flowers (Zvi et al., 2012).

From the observation of how pigmentation patterns diverged during evolution we learned that MYB regulators of anthocyanin biosynthesis are the best tool to alter anthocyanin production without affecting other processes. This is because their bHLH and WDR partners are involved in several other processes and changes in their activity would either be insufficient or have 


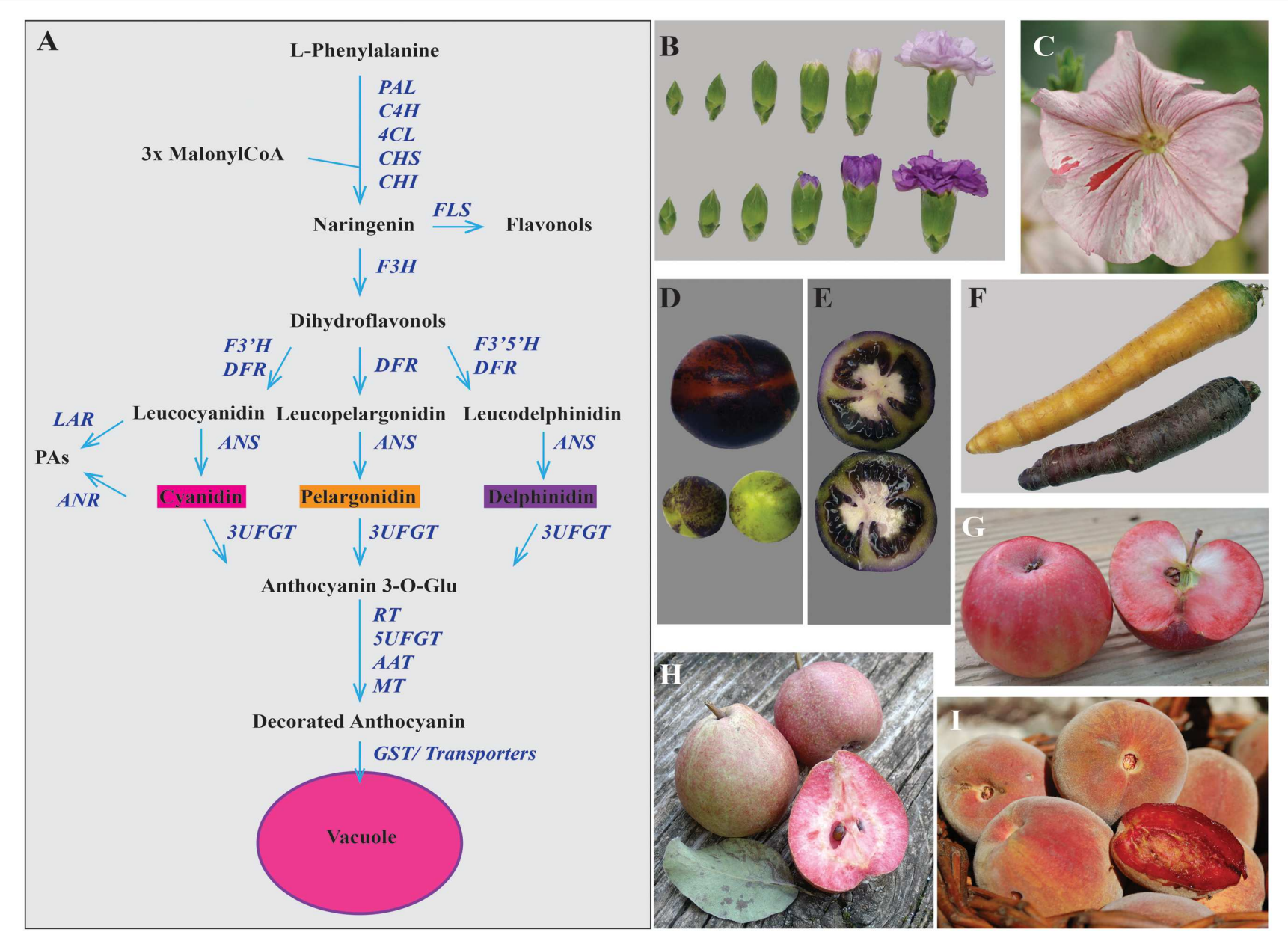

FIGURE 1 | Anthocyanin accumulation in different plant products. (A) Scheme of the biosynthetic pathway for different flavonoid pigments among which anthocyanins. The main enzymes catalyzing the reactions in the pathway are reported in blue. PAL, phenylalanine ammonia-lyase; C4H, cinnamate 4-hydroxylase; 4CL, 4-coumarate-COA ligase; CHS, chalcone synthase; CHI, chalcone isomerase; FLS, flavonol synthase; F3H, flavonoid 3 hydroxylase; F $3^{\prime} H$, flavonol $3^{\prime}$ hydroxylase; F $3^{\prime} 5^{\prime} H$, flavonol $3^{\prime}, 5^{\prime}$ hydroxylase; DFR, dihydroflavonol 4-reductase; LAR, leucoanthocyanidin reductase; ANR, anthocyanidin reductase; ANS, anthocyanidin synthase; 3UFGT, UDP glucose:flavonoid 3-O-glucosyltransferase; RT, rhamnosylation at three; 5UFGT: glucose:flavonoid 5-O-glucosyltransferase; AAT, anthocyanin acyltransferase; MT, methyltransferase; GST, glutathione S-transferase. PAs, proanthocyanidins. In (B) Moondust (up) and Moonshadow (down) transgenic carnations produced by Florigene/Suntory; (C) Petunia ph6 unstable mutant (transposon insertion) in the hybrid W138xR153 background. The red spots and sectors are due to PH6 reversion. In (D) transgenic tomato fruits from plants expressing the 35S:SIANT1 construct. Immature green and red ripe fruits with anthocyanin-rich sectors in the peel; (E) green tomatoes from the same plants as in (D) showing purple flesh, locular cavities and seeds. (F) Orange and purple carrots. In (G), (H), and (I) ancient varieties of Rosaceae species with anthocyanin-rich flesh. These fruits are locally known as: (G) "mela rossa dentro incarnato" (apple variety), (H) "pera cocomerina" (pear variety) and (I) "pesca sanguinella" (peach variety).

pleiotropic effects. Factors affecting pigment production more indirectly, like hormones, sugar concentration (Loreti et al., 2008; Zhou et al., 2009) or high light and cold (Lotkowska et al., 2015; Zhang et al., 2015a), usually have dramatic side effects on the plant physiology.

The picture of anthocyanin synthesis and regulation gained from studies in flowers was confirmed in several crops where homolog MBW complexes regulate pigment accumulation in different plant parts.

Modern crops are the result of a domestication process that, for most species, went on for the last 10.000 years. Selection resulted sometimes in the loss of pigmentation in some plant parts. Pigmentation in tomato fruits, for example, was probably a trait indirectly counter-selected by breeding as the fruits of several closely related wild Solanum species are colored. The introgression in domesticated tomato of two loci, Aft (Anthocyanin fruit) and atv (atroviolacea) from wild Solanum, results in the accumulation of anthocyanins in the epidermis and the pericarp of the fruit (Povero et al., 2011), indicating that it is possible to restore fruit pigmentation by adding few genes. In fact, ectopic expression of any of the R2R3-MYB genes SlAN2 and SlANT1 (Kiferle et al., 2015) is sufficient to get purple tomatoes (Figures 1D,E). As SlAN2 and SIANT1 proteins activate the whole biosynthetic pathway and stress can activate SlAN2 transcription, lack of pigmentation in cultivated tomato fruits is not due to mutations in enzyme encoding genes or to 
loss of function of one of the two MYBs. Rather, changes in the regulation of the MYBs, resulted in inactivity in fruits. Expression of DELILA and ROSEA1 (respectively a bHLH and a MYB) from snapdragon result in intensely purple tomatoes fruits which have health-promoting effects in a mouse model (Butelli et al., 2008). High expression of a different type of MYB (MYB12) in tomato stimulates the production of complex mixtures of flavonoids, by reprogramming primary metabolism toward the production of substrates for the phenylpropanoid pathway. The combination of MYB12 and transcription factors specific for the anthocyanin pathway further boosts anthocyanin production (Zhang et al., 2015c).

MYB genes are also responsible for pigmentation also in grape berries (Kobayashi et al., 2002; Walker et al., 2007), blood oranges (Butelli et al., 2012), apples and pears (Takos et al., 2006; Ban et al., 2007; Yuan et al., 2014). Some apple genotypes show red flesh and share a single ancestor, the Malus sieversii f. niedzwetzkyana wild apple native of Central Asia (Harris et al., 2002). The expression pattern of MdMYB10 in red flesh apples correlates with anthocyanin gene expression (Espley et al., 2007), and a minisatellite-like structure in its promoter increases MdMYB10 transcription and the accumulation of anthocyanin in leaves, flowers, and fruit cortex (Espley et al., 2009). Max Red Bartlett, a red-skinned European pear variety, gives occasionally greenskinned fruits in which PcMYB10 expression is silenced due to the methylation of two regions in its promoter (Wang et al., 2013).

The purple cauliflower (Brassica oleracea var. botrytis) originates from a spontaneous mutant found in a cauliflower field over 20 years ago (Chiu et al., 2010). This mutation results in upregulation of transcription of the $\operatorname{Pr}$ gene encoding for a MYB. Purple varieties are also known for carrots (Figure 1F), onions and potato (De Jong et al., 2004). Several more examples could be added to this list, showing that MYBs are indeed "master regulators" of anthocyanin biosynthesis and their expression pattern determines pigmentation patterns in plants.

The market request of high anthocyanin content food, led to the rediscovery of pigment-rich varieties, which were nearly forgotten. These ancient varieties of apples, pears and peaches (Figures 1G-I) are still poorly studied, but are a priceless source of interesting alleles to be introduced into market varieties.

Selection in agriculture probably favors mutations in MYB genes, over mutations in their bHLH and WD40 partners or in structural genes, because they are the least pleiotropic and because gain of function mutations are more likely to activate anthocyanin synthesis in new tissues. Strategies for improving anthocyanin production in crops by both breeding and genetic engineering mimics natural selection, acting on MYBs to tune the expression of anthocyanin structural genes.

\section{HIGHER PRODUCTION NOT ALWAYS MEANS HIGHER YIELD, AT LEAST FOR ANTHOCYANINS}

There are now sufficient tools to improve pigment production and color displayed by fruits and flowers. However, we have little understanding of the role played by degradation of anthocyanins on the total yield in fruits and on color in flowers.

It is often taken for granted that anthocyanins, once accumulated in the vacuole, are stable. However, few studies describe anthocyanin turn over and addressed whether this is due to enzymatic activity, spontaneous reactions or a combination of both (Oren-Shamir, 2009).

Color fading is reported for several species and here we briefly summarize illustrative examples reported in literature and/or known from everyday life.

In some plants, anthocyanins protect the photosynthetic apparatus from light damage in young leaves, and are lost later in development, enabling more light to enter the tissues (Steyn et al., 2002, 2004; Nissim-Levi et al., 2003). Instead, apple and pear peels show changes in pigmentation in response to temperature and/or light (Figures 2D-F; Steyn et al., 2004, 2009). In blood oranges, on the other end, anthocyanin content reaches a maximum in the fully ripe fruit, to decreases at latter stages when $\beta$-D-Glucosidase activity increases giving the formation of aglycons which are possible substrates for degradation by polyphenol oxidase, abundant in these fruits (Barbagallo et al., 2007). Polyphenol oxidases are also suspected to induce fading together with peroxidases in litchi fruits (Reichel et al., 2011) where an anthocyanin degradation enzyme (ADE) was identified as vacuolar laccase secreted to the extracellular space at pericarp browning (Fang et al., 2015).

Flowers turned out to be an excellent model to study color fading, which is observed for instance, in peony (Figure 2A), Hibiscus, orchids (Burg and Dijkman, 1967; Zhao et al., 2012; Shimokawa et al., 2015), dahlias (Figure 2B) and several Solanum species (Figure 2C). In commercial varieties of flowers, fading strongly affects the market value. One of these is aster, where the inhibition of color fading by magnesium is suggested to come from the formation of pigment-metal complexes (ShakedSachray et al., 2002). Although similar results were reported for grape cell suspensions (Sinilal et al., 2011), there is no direct evidence for the presence of metalloanthocyanin in these species.

Also the petals of Brunfelsia calycina, a Solanaceae shrub, fade from blue to complete white within few days after flower opening (Vaknin et al., 2005). Protein and mRNA synthesis inhibitors prevent anthocyanin degradation in these petals suggesting that fading is an active process. Interestingly, cytokinin treatment delays petal senescence but not anthocyanin degradation, suggesting that fading is independent from petal senescence and the accompanying increase in $\mathrm{pH}$. Peroxidase activity correlates in time with anthocyanin degradation and recently, Zipor et al. (2015) characterized a candidate vacuolar peroxidase, $B c \operatorname{Pr} x 01$, which transcript and protein level increase during fading. Furthermore, total protein extracts from brunfelsia petals induce in vitro fading of anthocyanins with different decorations extracted from petunia petals after addition of $\mathrm{H}_{2} \mathrm{O}_{2}$, suggesting a not substrate-specific mechanism. However, direct evidence that this in vivo reaction mimics the degradation seen in vivo is currently lacking.

The color of anthocyanins is affected by the $\mathrm{pH}$ of the vacuolar lumen where they accumulate. A strongly acidic lumen results in red, and a less acidic one in blue. In Petunia, 

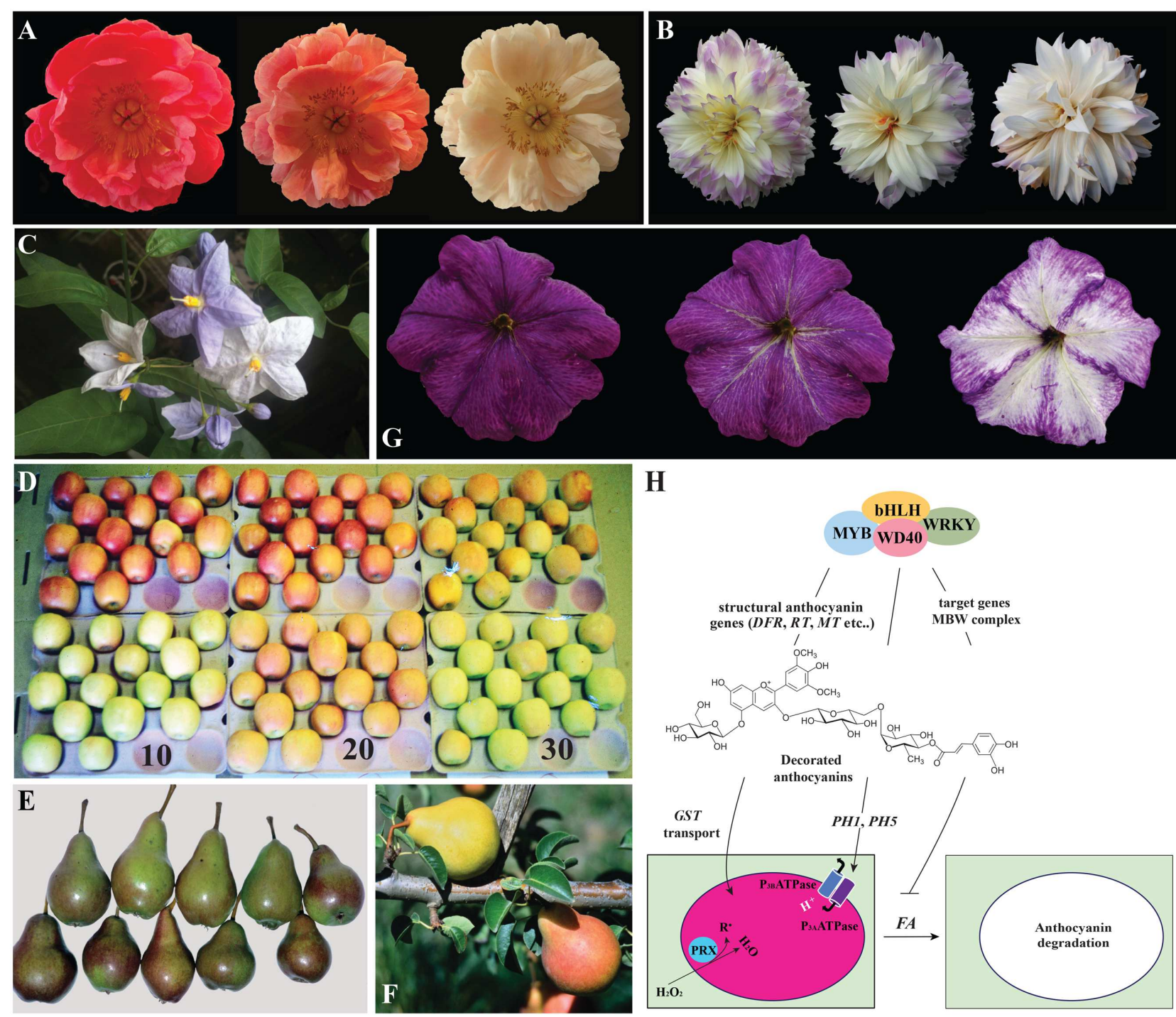

FIGURE 2 | Anthocyanin degradation in plants. (A) The same peony flower photographed different days (between the first and the last picture are 6 days) after opening. In (B) the same dahlia flower photographed at different days (between the first and the last pictures are about 2 weeks). (C) Solamun wrightii flowers photographed on the plant. The young buds and just open flowers are intensely pigmented, while older flowers are totally white indicating strong fading of the anthocyanin pigments. (D) Color change in red (upper row) and green (bottom row) 'Cripps Pink' apples exposed to moderate light at 10, 20, and $30^{\circ} \mathrm{C}$ for 6 days. The green apples accumulated anthocyanin at $20^{\circ} \mathrm{C}$ while the red apples loose anthocyanin at $30^{\circ} \mathrm{C}$ (Steyn et al., 2004). (E) Bleaching of red color (upper row) at the sun-exposed side of Rosemarie fruits compared to fruits receiving less intense light (bottom row) which maintain more intense pigmentation. (F) Rosemarie pears: one fruit has lost its red color and turned yellow on the tree. This phenomenon is reported for Rosemarie pears fruits that bent over during development resulting in pinching of the peduncle. (G) Petunia flower photographed at different moments after opening and showing strong color fading. This is a ph4 mutant line in a FADING background accumulating malvidin. (H) Scheme summarizing our present understanding of color fading in plant cells. Similar transcription factor complexes consisting of MYB, bHLH, WD40 and WRKY factors control anthocyanin biosynthesis (through the transcription of the structural genes encoding for the enzymes of the pathway) and vacuolar acidification (through the transcription of the two pumps PH1 and PH5). Anthocyanin are sequestered to the vacuolar lumen. When the anthocyanin molecules are highly decorated and a dominant allele of the FADING (FA) gene is present, color fading takes place as consequence of anthocyanin degradation, probably in the vacuolar lumen. This mechanism is blocked by the activity of the MBW complex indicating that target genes of these transcription factors might protect anthocyanins from the effect of $F A$.

blue flowering mutants define the loci $\mathrm{PH} 1$ to $\mathrm{PH}$ (Koes et al., 2005) which control vacuolar acidification in petals. PH1 and $\mathrm{PH} 5$ encode a heteromeric proton pump, transcriptionally controlled by the AN1-PH4-AN11-PH3 complex (a bHLH, a MYB, a WDR and a WRKY transcription factors) sharing components with the MBW complex regulating anthocyanin biosynthesis. Thus, pigment synthesis and vacuolar acidification are controlled by the same regulatory network (Verweij et al., 2008; Faraco et al., 2014). In petunia $p h 3, p h 4$ and $p h 6$ mutants that contain the dominant allele of the FADING (FA) locus (de Vlaming et al., 1982, 1983), nearly complete degradation of anthocyanin occurs after flower opening (Figure 2G). This 
process is restricted to the flower limb, while flower tube and pollen maintain their full color. Color fading is in petunia much stronger for highly substituted anthocyanins, such as 3-rutinosido(p-coumaroyl)-5glucoside anthocyanins, whereas 3glucosides and 3-rutinosides only weakly fade and anthocyanin methylation has no effect (de Vlaming et al., 1982). As reported above, in vitro, brunfelsia protein extracts equally destabilize differently substituted anthocyanins from petunia (Zipor et al., 2015). This discrepancy might have different explanations: (i) the FA gene product has specificity for highly substituted anthocyanin molecules and the in vitro reaction does not reflect the one in vivo, (ii) the specificity of the fading mechanism in brunfelsia is different from the one in petunia, or (iii) FA activity is dependent on genes that genetically linked with genes determining the anthocyanin sunstituion patter, such as Rhamnosyl Transferase (RT) and Glucosylation at Five (GF; Quattrocchio et al., 2006).

Our limited understanding of the mechanism of anthocyanin fading, coming from experiments in brunfelsia and genetic analysis in petunia, is summarized in Figure $\mathbf{2 H}$. Decorated anthocyanin molecules are synthesized under the control of the MBW transcription complex and transported to the vacuolar lumen where their color is affected by the $\mathrm{pH}$ of the environment. This is determined by the PH1/PH5 pump which expression is also regulated by the MBW complex. In the vacuole, peroxidases modulate the concentration of free radicals and water peroxide, which can affect anthocyanin stability. Under these conditions anthocyanins are relatively stable (also in the presence of the FA allele), as compared to mutants for the MBW complex which are depleted in expression of all its target genes.

On the contrary of what suggested elsewhere (Oren-Shamir, 2009), fading in petunia is not merely a change in color due to high vacuolar $\mathrm{pH}$ in mutants. Mutations in $\mathrm{PH} 1$ and $\mathrm{PH} 5$ increase vacuolar $\mathrm{pH}$ in the same extent than mutations in the MBW complex, but are not accompanied by color loss (Verweij et al., 2008; Faraco et al., 2014). Fading in ph4, ph3, and ph6 must therefore be due to down-regulation of other target genes of the MBW complex (Quattrocchio et al., 2006) in combination with the presence of a dominant FADING allele (de Vlaming et al., 1982).

The MBW complex controls several genes encoding enzymes of the anthocyanin pathway (Quattrocchio et al., 1998; Spelt et al., 2000), PH1 and PH5 (Verweij et al., 2008; Faraco et al., 2014) and at least 10 others of unknown function (Verweij et al., 2008). Which of these genes protect anthocyanins from the action of FADING can only be speculated. Their characterization via loss and gain of function study will shed light on this point, and will unravel which cellular mechanism protects anthocyanins from massive degradation.

The occurrence of fading obviously affects the final yield of anthocyanins diminishing the effect of synthesis improvement achieved by breeding or transgenesis (e.g., by modulation of the expression of MYB regulators). For this reason, the identification of the factors controlling fading of pigments as well as its inhibition, opens possibilities of further improvement of the content of these compounds in the final plant products.

\section{CONCLUSION}

Anthocyanin-rich plants produced by traditional breeding or biotechnology, could contribute to human health reducing the incidence of major diseases (Martin et al., 2011), while new flower colors and patterns (Yoshida et al., 2009; Tanaka and Brugliera, 2013; Zhao and Tao, 2015) are interesting for the ornamental market. Success was booked in producing plants with enhanced anthocyanin synthesis by increasing the expression of MYB factors that activate transcription of structural anthocyanin genes. However, degradation also contributes to the final anthocyanin yield in plant products making the understanding of this phenomenon important for future strategies of crop improvement.

Studies in brunfelsia provide insight into the biochemistry of anthocyanin degradation (Zipor et al., 2015).

It is unclear whether a certain degree of anthocyanin degradation, is functional to the plant. So far only speculations are possible. Anthocyanins protect tissues from free radicals and in some species accumulate in seedlings where they shield the photosynthetic machinery from light. Their degradation later in development probably improves photosynthesis (Gould et al., 2002b). In brunfelsia, anthocyanin degradation in flowers is accompanied by release of fragrant volatiles and both processes could be signals for pollinators (Zipor et al., 2015). However, no evidence is available for correlations between the two phenomena. Reactive oxygen species (ROS) formed in aging flowers or maturing fruits from photooxidation, photorespiration, and Mehler reaction, could induce anthocyanin degradation and this might protect other cellular components from damages (Hernández et al., 2009). Moreover anthocyanins inhibit Fenton hydroxyl radical generation by scavenging superoxide and hydrogen peroxide (Gould et al., 2002a, 2010). A better characterization of the genes/factors involved in color fading will answer to the many questions we presented here and open the possibility to 'design' plant cells with stable vacuolar content. Mutants makes it possible to approach the characterization of the FADING locus and of the MBW target genes involved in anthocyanin stabilization. Considering that anthocyanins are not stable outside the vacuole (Mueller et al., 2000), the MBW complex could control vacuolar physiology and mutants might have vacuolar defect resulting in anthocyanin leakage. Factors involved in both fading and its prevention could function in totally unrelated pathways. Their participation in massive anthocyanin degradation might be a peculiarity of rare genotypes that amplify a moderate pigment loss normally occurring after vacuolar accumulation.

Genetic analyses in species, like petunia, where well-defined mutants affecting this phenomenon are available (de Vlaming et al., 1982, 1983; Quattrocchio et al., 2006) open the way to identify the genes that determine anthocyanin trun-over in vivo, to assess whether complete disappearance of color is an "accident" originating from human selection during crop domestication, and to gain tools to improve stabilization of anthocyanin (and possibly also other products) in the vacuolar lumen. 


\section{AUTHOR CONTRIBUTIONS}

VP has searched the literature, collected the photographic information and written the manuscript. FQ and RK have conceived the idea and helped with writing the manuscript.

\section{FUNDING}

VP is supported by a grant of the Nederlandse Organisatie voor Wetenschappelijk Onderzoek (Project Number: 824.14.024).

\section{REFERENCES}

Ban, Y., Honda, C., Hatsuyama, Y., Igarashi, M., Bessho, H., and Moriguchi, T. (2007). Isolation and functional analysis of a MYB transcription factor gene that is a key regulator for the development of red coloration in apple skin. Plant Cell Physiol. 48, 958-970. doi: 10.1093/pcp/pcm066

Barbagallo, R. N., Palmeri, R., Fabiano, S., Rapisarda, P., and Spagna, G. (2007). Characteristic of $\beta$-glucosidase from Sicilian blood oranges in relation to anthocyanin degradation. Enzyme Microbiol. Technol. 41, 570-575. doi: 10.1016/j.enzmictec.2007.05.006

Burg, S. P., and Dijkman, M. J. (1967). Ethylene and auxin participation in pollen induced fading of vanda orchid blossoms. Plant Physiol. 42, 1648-1650. doi: 10.1104/pp.42.11.1648

Butelli, E., Licciardello, C., Zhang, Y., Liu, J., Mackay, S., Bailey, P., et al. (2012). Retrotransposons control fruit-specific, cold-dependent accumulation of anthocyanins in blood oranges. Plant Cell 24, 1242-1255. doi: 10.1105/tpc.111.095232

Butelli, E., Titta, L., Giorgio, M., Mock, H.-P., Matros, A., Peterek, S., et al. (2008). Enrichment of tomato fruit with health-promoting anthocyanins by expression of select transcription factors. Nat. Biotechnol. 26, 1301-1308. doi: $10.1038 /$ nbt. 1506

Chanoca, A., Kovinich, N., Burkel, B., Stecha, S., Bohorquez-Restrepo, A., Ueda, T., et al. (2015). Anthocyanin vacuolar inclusions form by a microautophagy mechanism. Plant Cell 27, 2545-2559. doi: 10.1105/tpc.15.00589

Chiu, L.-W., Zhou, X., Burke, S., Wu, X., Prior, R. L., and Li, L. (2010). The purple cauliflower arises from activation of a MYB transcription factor. Plant Physiol. 154, 1470-1480. doi: 10.1104/pp.110.164160

De Jong, W. S., Eannetta, N. T., De Jong, D. M., and Bodis, M. (2004). Candidate gene analysis of anthocyanin pigmentation loci in the Solanaceae. Theor. Appl. Genet. 108, 423-432. doi: 10.1007/s00122-003-1455-1

de Vlaming, P., Schram, A. W., and Wiering, H. (1983). Genes affecting flower colour and $\mathrm{pH}$ of flower limb homogenates in Petunia hybrida. Theor. Appl. Genet. 66, 271-278. doi: 10.1007/BF00251158

de Vlaming, P., van Eekeres, J. E. M., and Wiering, H. (1982). A gene for flower colour fading in Petunia hybrida. Theor. Appl. Genet. 61, 41-46. doi: $10.1007 / \mathrm{BF} 00261508$

Du, H., Wu, J., Ji, K.-X., Zeng, Q.-Y., Bhuiya, M.-W., Su, S., et al. (2015). Methylation mediated by an anthocyanin, $\mathrm{O}$-methyltransferase, is involved in purple flower coloration in Paeonia. J. Exp. Bot. 66, 6563-6577. doi: 10.1093/jxb/erv365

Espley, R. V., Brendolise, C., Chagné, D., Kutty-Amma, S., Green, S., Volz, R., et al. (2009). Multiple repeats of a promoter segment causes transcription factor autoregulation in red apples. Plant Cell 21, 168-183. doi: 10.1105/tpc.108.059329

Espley, R. V., Hellens, R. P., Putterill, J., Stevenson, D. E., Kutty-Amma, S., and Allan, A. C. (2007). Red colouration in apple fruit is due to the activity of the MYB transcription factor, MdMYB10. Plant J. 49, 414-427. doi: 10.1111/j.1365313X.2006.02964.X

Fang, F., Zhang, X., Luo, H., Zhou, J., Gong, Y., Li, W., et al. (2015). An intracellular laccase is responsible for the epicatechin mediated anthocyanin degradation in litchi fruit pericarp. Plant Physiol. 169, 2391-2408. doi: 10.1104/pp.15.00359

Faraco, M., Spelt, C., Bliek, M., Verweij, W., Hoshino, A., Espen, L., et al. (2014). Hyperacidification of vacuoles by the combined action of two different

\section{ACKNOWLEDGMENTS}

The authors are grateful to Dr. Isabella Dalla Ragione, president of Archeologia Arborea Foundation (non-profit organization) for the safeguard and conservation of the vegetal genetic inheritance (Perugia, Italy) and for providing the pictures in Figures 1G-I. Pictures in Figures 2D-F were kindly provided by Dr. Wiehann Steyn, Department of Horticultural Science, University of Stellenbosch, South Africa. The picture in Figure 2B was kindly provided by Vivina Morea.

P-ATPases in the tonoplast determines flower color. Cell Rep. 6, 32-43. doi: 10.1016/j.celrep.2013.12.009

Forbes-Hernandez, T. Y., Gasparrini, M., Afrin, S., Bompadre, S., Mezzetti, B., Quiles, J. L., et al. (2015). The healthy effects of strawberry polyphenols: which strategy behind antioxidant capacity? Crit. Rev. Food Sci. Nutr. doi: 10.1080/10408398.2015.1051919 [Epub ahead of print].

Forkmann, G., and Heller, W. (1999). "1.26 - biosynthesis of flavonoids", in Comprehensive Natural Products Chemistry, eds E.-C. O. Meth-Cohn, S. D. Barton, and K. Nakanishi (Pergamon: Elsevier), 713-748.

Francisco, R. M., Regalado, A., Ageorges, A., Burla, B. J., Bassin, B., Eisenach, C., et al. (2013). ABCC1, an ATP binding cassette protein from grape berry, transports anthocyanidin 3-O-Glucosides. Plant Cell 25, 1840-1854. doi: 10.1105/tpc.112.102152

Giampieri, F., Forbes-Hernandez, T. Y., Gasparrini, M., Alvarez-Suarez, J. M., Afrin, S., Bompadre, S., et al. (2015). Strawberry as a health promoter: an evidence based review. Food Funct. 6, 1386-1398. doi: 10.1039/c5fo00147a

Gould, K. S., Dudle, D. A., and Neufeld, H. S. (2010). Why some stems are red: cauline anthocyanins shield photosystem II against high light stress. J. Exp. Bot. 61, 2707-2717. doi: 10.1093/jxb/erq106

Gould, K. S., McKelvie, J., and Markham, K. R. (2002a). Do anthocyanins function as antioxidants in leaves? Imaging of $\mathrm{H}_{2} \mathrm{O}_{2}$ in red and green leaves after mechanical injury. Plant Cell Environ. 25, 1261-1269. doi: 10.1046/j.13653040.2002.00905.X

Gould, K. S., Neill, S. O., and Vogelmann, T. C. (2002b). A unified explanation for anthocyanins in leaves? Adv. Bot. Res. 37, 167-192. doi: 10.1016/S00652296(02)37049-6

Guo, H., and Ling, W. (2015). The update of anthocyanins on obesity and type 2 diabetes: experimental evidence and clinical perspectives. Rev. Endocr. Metab. Disord. 16, 1-13. doi: 10.1007/s11154-014-9302-Z

Harris, S. A., Robinson, J. P., and Juniper, B. E. (2002). Genetic clues to the origin of the apple. Trends Genet. 18, 426-430. doi: 10.1016/S0168-9525(02)02689-6

Hernández, I., Alegre, L., Van Breusegem, F., and Munné-Bosch, S. (2009). How relevant are flavonoids as antioxidants in plants? Trends Plant Sci. 14, 125-132. doi: 10.1016/j.tplants.2008.12.003

Holton, T. A., and Tanaka, Y. (1994). Blue roses - a pigment of our imagination? Trends Biotechnol. 12, 40-42. doi: 10.1016/0167-7799(94)90097-3

Hsu, C.-C., Chen, Y.-Y., Tsai, W.-C., Chen, W.-H., and Chen, H.-H. (2015). Three R2R3-MYB transcription factors regulate distinct floral pigmentation patterning in Phalaenopsis spp. Plant Physiol. 168, 175-191. doi: 10.1104/pp.114.254599

Hu, D. G., Sun, C. H., Ma, Q. J., You, C. X., and Cheng, L. H. Y. (2016). PMdMYB1 regulates anthocyanins and malate accumulation by directly facilitating their transport into the vacuole in apples. Plant Physiol. doi: 10.1104/pp.15.01333 [Epub ahead of print].

Itoh, Y., Higeta, D., Suzuki, A., and Yoshida, H. O. Y. (2002). Excision of transposable elements from the chalcone isomerase and dihydroflavonol 4reductase genes may contribute to the variegation of the yellow-flowered carnation (Dianthus caryophyllus). Plant Cell Physiol. 43, 578-585. doi: $10.1093 / \mathrm{pcp} / \mathrm{pcf065}$

Jaakola, L. (2013). New insights into the regulation of anthocyanin biosynthesis in fruits. Trends Plant Sci. 18, 477-483. doi: 10.1016/j.tplants.2013.06.003

Kalt, W., McDonald, J. E., Fillmore, S., and Tremblay, F. (2014). Blueberry effects on dark vision and recovery after photo-bleaching: placebo-controlled 
cross-over studies. J. Agric. Food Chem. 62, 11180-11189. doi: 10.1021/jf50 3689 c

Katsumoto, Y., Fukuchi-Mizutani, M., Fukui, Y., Brugliera, F., Holton, T. A., Karan, M., et al. (2007). Engineering of the rose flavonoid biosynthetic pathway successfully generated blue-hued flowers accumulating delphinidin. Plant Cell Physiol. 48, 1589-1600. doi: 10.1093/pcp/pcm131

Kiferle, C., Fantini, E., Bassolino, L., Povero, G., Spelt, C., Buti, S., et al. (2015). Tomato R2R3-MYB Proteins SlANT1 and SlAN2: same protein activity, different roles. PLoS ONE 10:e0136365. doi: 10.1371/journal.pone.0136365

Kobayashi, S., Ishimaru, M., Hiraoka, K., and Honda, C. (2002). Myb-related genes of the Kyoho grape (Vitis labruscana) regulate anthocyanin biosynthesis. Planta 215, 924-933. doi: 10.1007/s00425-002-0830-5

Koes, R., Verweij, W., and Quattrocchio, F. (2005). Flavonoids: a colorful model for the regulation and evolution of biochemical pathways. Trends Plant Sci. 10, 236-242. doi: 10.1016/j.tplants.2005.03.002

Lister, C., Jackson, D., and Martin, C. (1993). Transposon-induced inversion in Antirrhinum modifies nivea gene expression to give a novel flower color pattern under the control of cycloidea radialis. Plant Cell 5, 1541-1553. doi: $10.2307 / 3869737$

Loreti, E., Povero, G., Novi, G., Solfanelli, C., Alpi, A., and Perata, P. (2008). Gibberellins, jasmonate and abscisic acid modulate the sucrose-induced expression of anthocyanin biosynthetic genes in Arabidopsis. New Phytol. 179, 1004-1016. doi: 10.1111/j.1469-8137.2008.02511.x

Lotkowska, M. E., Tohge, T., Fernie, A. R., Xue, G.-P., Balazadeh, S., and MuellerRoeber, B. (2015). The Arabidopsis transcription factor MYB112 promotes anthocyanin formation during salinity and under high light stress. Plant Physiol. 169, 1862-1880. doi: 10.1104/pp.15.00605

Martin, C., Butelli, E., Petroni, K., and Tonelli, C. (2011). How can research on plants contribute to promoting human health? Plant Cell 23, 1685-1699. doi: 10.1105/tpc.111.083279

Meyer, P., Heidmann, I., Forkmann, G., and Saedler, H. (1987). A new petunia flower colour generated by transformation of a mutant with a maize gene. Nature 330, 677-678. doi: 10.1038/330677a0

Morita, Y., Ishiguro, K., Tanaka, Y., Iida, S., and Hoshino, A. (2015). Spontaneous mutations of the UDP-glucose: flavonoid 3-O-glucosyltransferase gene confers pale- and dull-colored flowers in the Japanese and common morning glories. Planta 242, 575-587. doi: 10.1007/s00425-015-2321-5

Mueller, L. A., Goodman, C. D., Silady, R. A., and Walbot, V. (2000). AN9, a petunia glutathione S-transferase required for anthocyanin sequestration, is a flavonoid-binding protein. Plant Physiol. 123, 1561-1570. doi: 10.1104/pp.123.4.1561

Nesi, N., Jond, C., Debeaujon, I., Caboche, M., and Lepiniec, L. (2001). The Arabidopsis $\mathrm{TT}_{2}$ gene encodes an $\mathrm{R}_{2} \mathrm{R}_{3}$ MYB domain protein that acts as a key determinant for proanthocyanidin accumulation in developing seed. Plant Cell 13, 2099-2114. doi: 10.2307/3871430

Nissim-Levi, A., Kagan, S., Ovadia, R., and Oren-Shamir, M. (2003). Effects of temperature, UV-light and magnesium on anthocyanin pigmentation in cocoplum leaves. J. Hortic. Sci. Biotechnol. 78, 61-64.

Olejnik, A., Rychlik, J., Kidoń, M., Czapski, J., Kowalska, K., Juzwa, W., et al. (2016). Antioxidant effects of gastrointestinal digested purple carrot extract on the human cells of colonic mucosa. Food Chem. 190, 1069-1077. doi: 10.1016/j.foodchem.2015.06.080

Oliveira, A., and Pintado, M. (2015). Stability of polyphenols and carotenoids in strawberry and peach yoghurt throughout in vitro gastrointestinal digestion. Food Funct. 6, 1611-1619. doi: 10.1039/c5fo00198f

Oren-Shamir, M. (2009). Does anthocyanin degradation play a significant role in determining pigment concentration in plants? Plant Sci. 177, 310-316. doi: 10.1016/j.plantsci.2009.06.015

Povero, G., Gonzali, S., Bassolino, L., Mazzucato, A., and Perata, P. (2011). Transcriptional analysis in high-anthocyanin tomatoes reveals synergistic effect of Aft and atv genes. J. Plant Physiol. 168, 270-279. doi: 10.1016/j.jplph.2010.07.022

Provenzano, S., Spelt, C., Hosokawa, S., Nakamura, N., Brugliera, F., Demelis, L., et al. (2014). Genetic control and evolution of anthocyanin methylation. Plant Physiol. 165, 962-977. doi: 10.1104/pp.113.234526

Quattrocchio, F., Verweij, W., Kroon, A., Spelt, C., Mol, J., and Koes, R. (2006). $\mathrm{PH} 4$ of Petunia is an $\mathrm{R}_{2} \mathrm{R}_{3}$ MYB protein that activates vacuolar acidification through interactions with basic-helix-loop-helix transcription factors of the anthocyanin pathway. Plant Cell 18, 1274-1291. doi: 10.1105/tpc.105. 034041

Quattrocchio, F., Wing, J. F., Van der Woude, K., Mol, J. N. M., and Koes, R. (1998). Analysis of bHLH and MYB domain proteins: species-specific regulatory differences are caused by divergent evolution of target anthocyanin genes. Plant J. 13, 475-488. doi: 10.1046/j.1365-313X.1998.00046.x

Ramsay, N. A., and Glover, B. J. (2005). MYB - bHLH - WD40 protein complex and the evolution of cellular diversity. Trends Plant Sci. 10, 63-70. doi: 10.1016/j.tplants.2004.12.011

Reichel, M., Carle, R., Sruamsiri, P., and Neidhart, S. (2011). Changes in flavonoids and nonphenolic pigments during on-tree maturation and postharvest pericarp browning of litchi (Litchi chinensis Sonn.) as shown by HPLC-MSn. J. Agric. Food Chem. 59, 3924-3939. doi: 10.1021/jf104432r

Rinaldo, A., Cavallini, E., Jia, Y., Moss, S. M. A., McDavid, D. A. J., Hooper, L. C., et al. (2015). A grapevine anthocyanin acyltransferase, transcriptionally regulated by VvMYBA, can produce most acylated anthocyanins present in grape skins. Plant Physiol. 169, 1897-1916. doi: 10.1104/pp.15.01255

Samadi, A. K., Bilsland, A., Georgakilas, A. G., Amedei, A., Amin, A., Bishayee, A., et al. (2015). A multi-targeted approach to suppress tumor-promoting inflammation. Semin. Cancer Biol. 35, 1-34. doi: 10.1016/j.semcancer.2015.03.006

Shaked-Sachray, L., Weiss, D., Reuveni, M., Nissim-Levi, A., and Oren-Shamir, M. (2002). Increased anthocyanin accumulation in aster flowers at elevated temperatures due to magnesium treatment. Physiol. Plant. 114, 559-565. doi: 10.1034/j.1399-3054.2002.1140408.x

Sheehan, H., Moser, M., Klahre, U., Esfeld, K., Dell'Olivo, A., Mandel, T., et al. (2015). MYB-FL controls gain and loss of floral UV absorbance, a key trait affecting pollinator preference and reproductive isolation. Nat Genet. Adv. 48, 159-166. doi: $10.1038 / \mathrm{ng} .3462$

Shimokawa, S., Iwashina, T., and Murakami, N. (2015). Flower color changes in three Japanese hibiscus species: further quantitative variation of anthocyanin and flavonols. Nat. Prod. Commun. 10, 451-452.

Sinilal, B., Ovadia, R., Nissim-Levi, A., Perl, A., Carmeli-Weissberg, M., and Oren-Shamir, M. (2011). Increased accumulation and decreased catabolism of anthocyanins in red grape cell suspension culture following magnesium treatment. Planta 234, 61-71. doi: 10.1007/s00425-0111377-0

Spelt, C., Quattrocchio, F., Mol, J. N., and Koes, R. (2000). Anthocyanin1 of petunia encodes a basic helix-loop-helix protein that directly activates transcription of structural anthocyanin genes. Plant Cell 12, 1619-1632. doi: 10.1105/tpc.12.9.1619

Steyn, W. J., Holcroft, D. M., and Wand, S. J. E. (2004). Anthocyanin degradation in detached pome fruit with reference to preharvest red color loss and pigmentation patterns of blushed and fully red pears. J. Am. Soc. Hort. Sci. 129, 13-19.

Steyn, W. J., Wand, S. J. E., Holcroft, D. M., and Jacobs, G. (2002). Anthocyanins in vegetative tissues: anthocyanins in unified function a proposed photoprotection. New Phytol. 155, 349-361. doi: 10.1046/j.14698137.2002.00482.x

Steyn, W. J., Wand, S. J. E., Jacobs, G., Rosecrance, R. C., and Roberts, S. C. (2009). Evidence for a photoprotective function of low-temperature-induced anthocyanin accumulation in apple and pear peel. Physiol. Plant. 136, 461-472. doi: 10.1111/j.1399-3054.2009.01246.x

Stracke, R., Werber, M., and Weisshaar, B. (2001). The R2R3-MYB gene family in Arabidopsis thaliana. Curr. Opin. Plant Biol. 4, 447-456. doi: 10.1016/S13695266(00)00199-0

Takos, A. M., Jaffé, F. W., Jacob, S. R., Bogs, J., Robinson, S. P., and Walker, A. R. (2006). Light-induced expression of a MYB gene regulates anthocyanin biosynthesis in red apples. Plant Physiol. 142, 1216-1232. doi: 10.1104/pp.106.088104

Tanaka, Y., and Brugliera, F. (2013). Flower colour and cytochromes P450. Philos. Trans. R. Soc. Lond. B. Biol. Sci. 368:20120432. doi: 10.1098/rstb.2012.0432

Tanaka, Y., Sasaki, N., and Ohmiya, A. (2008). Biosynthesis of plant pigments: anthocyanins, betalains and carotenoids. Plant J. 54, 733-749. doi: 10.1111/j.1365-313X.2008.03447.x

Titta, L., Trinei, M., Stendardo, M., Berniakovich, I., Petroni, K., Tonelli, C., et al. (2010). Blood orange juice inhibits fat accumulation in mice. Int. J. Obes. (Lond). 34, 578-588. doi: 10.1038/ijo.2009.266 
Tornielli, G., Koes, R. E., and Quattrocchio, F. (2009). "The genetics of flower color," in Petunia: Evolutionary, Developmental and Physiological Genetics, eds T. Gerats and J. Strommer (Berlin: Springer), 445. Available at: http://books.go ogle.com/books?id=JK3Fb0yd5z8C\&pgis $=1$

Vaknin, H., Bar-Akiva, A., Ovadia, R., Nissim-Levi, A., Forer, I., Weiss, D., et al. (2005). Active anthocyanin degradation in Brunfelsia calycina (yesterday-todaytomorrow) flowers. Planta 222, 19-26. doi: 10.1007/s00425-005-1509-5

Verweij, W., Spelt, C., Di Sansebastiano, G.-P., Vermeer, J., Reale, L., Ferranti, F., et al. (2008). An $\mathrm{H}^{+}$P-ATPase on the tonoplast determines vacuolar $\mathrm{pH}$ and flower colour. Nat. Cell Biol. 10, 1456-1462. doi: 10.1038/ncb1805

Vlachojannis, C., Zimmermann, B. F., and Chrubasik-Hausmann, S. (2015). Efficacy and safety of pomegranate medicinal products for cancer. Evid. Based Complement. Alternat. Med. 2015:258598. doi: 10.1155/2015/258598

Walker, A. R., Lee, E., Bogs, J., Mcdavid, D. A. J., Thomas, M. R., and Robinson, S. P. (2007). White grapes arose through the mutation of two similar and adjacent regulatory genes. Plant J. 49, 772-785. doi: 10.1111/j.1365-313X.2006. 02997.x

Wang, Y., Zhang, D., Liu, Y., Wang, D., Liu, J., and Ji, B. (2015). The protective effects of berry-derived anthocyanins against visible light-induced damage in human retinal pigment epithelial cells. J. Sci. Food Agric. 95, 936-944. doi: $10.1002 /$ jsfa. 6765

Wang, Z., Meng, D., Wang, A., Li, T., Jiang, S., Cong, P., et al. (2013). The methylation of the PcMYB10 promoter is associated with greenskinned sport in Max Red Bartlett pear. Plant Physiol. 162, 885-896. doi: 10.1104/pp.113.214700

Yoshida, K., Mori, M., and Kondo, T. (2009). Blue flower color development by anthocyanins: from chemical structure to cell physiology. Nat. Prod. Rep. 26, 884-915. doi: 10.1039/b800165k.

Yuan, K., Wang, C., and Wang, J. (2014). Analysis of the MdMYB1 gene sequence and development of new molecular markers related to apple skin color and fruit-bearing traits. Mol. Genet. Genomics 289, 1257-1265. doi: 10.1007/s00438014-0886-5

Zhang, C., Jia, H., Wu, W., Wang, X., Fang, J., and Wang, C. (2015a). Functional conservation analysis and expression modes of grape anthocyanin synthesis genes responsive to low temperature stress. Gene 574, 168-177. doi: 10.1016/j.gene.2015.08.003
Zhang, Y., Butelli, E., Alseekh, S., Tohge, T., Rallapalli, G., Luo, J., et al. (2015b). Multi-level engineering facilitates the production of phenylpropanoid compounds in tomato. Nat. Commun. 6, 1-11. doi: 10.1038/ncomms 9635

Zhang, Y., de Stefano, R., Robine, M., Butelli, E., Bulling, K., Hill, L., et al. (2015c). Different ROS-scavenging properties of flavonoids determine their abilities to extend shelf life of tomato. Plant Physiol. 169, 1568-1583. doi: 10.1104/pp.15.00346

Zhao, D., Hao, Z., and Tao, J. (2012). Effects of shade on plant growth and flower quality in the herbaceous peony (Paeonia lactiflora Pall.). Plant Physiol. Biochem. 61, 187-196. doi: 10.1016/j.plaphy.2012. 10.005

Zhao, D., and Tao, J. (2015). Recent advances on the development and regulation of flower color in ornamental plants. Front. Plant Sci. 6:261. doi: 10.3389/fpls.2015.00261

Zhou, X., Hua, D., Chen, Z., Zhou, Z., and Gong, Z. (2009). Elongator mediates ABA responses, oxidative stress resistance and anthocyanin biosynthesis in Arabidopsis. Plant J. 60, 79-90. doi: 10.1111/j.1365-313X.2009.03931.x

Zipor, G., Icia Duarte, P., Es Carqueijeiro, I., Shahar, L., Ovadia, R., TeperBamnolker, P., et al. (2015). In planta anthocyanin degradation by vacuolar class III peroxidase in Brunfelsia calycina flowers. New Phytol. 205, 653-665. doi: $10.1111 /$ nph. 13038

Zvi, M. M., Shklarman, E., Masci, T., Kalev, H., Debener, T., Shafir, S., et al. (2012). PAP1 transcription factor enhances production of phenylpropanoid and terpenoid scent compounds in rose flowers. New Phytol. 195, 335-345. doi: 10.1111/j.1469-8137.2012.04161.x

Conflict of Interest Statement: The authors declare that the research was conducted in the absence of any commercial or financial relationships that could be construed as a potential conflict of interest.

Copyright (C) 2016 Passeri, Koes and Quattrocchio. This is an open-access article distributed under the terms of the Creative Commons Attribution License (CC BY). The use, distribution or reproduction in other forums is permitted, provided the original author(s) or licensor are credited and that the original publication in this journal is cited, in accordance with accepted academic practice. No use, distribution or reproduction is permitted which does not comply with these terms. 